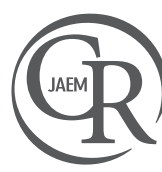

\section{A Life-threatening Complication of Deep Venous Thrombosis; Phlegmesia Cerulea Dolens}

\author{
Hayatı Tehdit Eden Derin Ven Trombozu Komplikasyonu; Phlegmesia Cerulea Dolens
}

\author{
Ömer Kaya' ${ }^{1}$ Neslihan Yücel², Gazi Gülbaş ${ }^{1}$, Hilal Ermiş', Ramazan Kutlu³ \\ 'İnönü Üniversitesi Tıp Fakültesi, Göğüs Hastalıkları Anabilim Dalı, Malatya, Türkiye \\ ¿̇nönü Üniversitesi Tıp Fakültesi, Acil Tıp Anabilim Dalı, Malatya, Türkiye \\ 3inönü Üniversitesi Tıp Fakültesi, Radyoloji Anabilim Dalı, Malatya, Türkiye
}

\begin{abstract}
Phlegmasia cerulea dolens is a rare condition caused by complete venous occlusion and often results in tissue necrosis, limb amputation, or death. In this study, a 51 year old female presenting at our emergency department with leg edema, leg pain and cyanosis and was diagnosed with phlegmesia cerulea dolens, which is a life-threatening complication of deep venous thrombosis. Prompt diagnosis and treatment initiation are important to prevent pulmonary emboli, gangrene, amputation, and, ultimately, death.
\end{abstract}

Keywords: Phlegmasia cerulea dolens, diagnosis, treatment Received: 05.01.2012 Accepted: 03.03.2012

\section{ÖZET}

Phlegmesia cerulea dolens tam venöz tıkanıklığın neden olduğu nadir bir durumdur. Sıklıkla doku nekrozu, ekstremitede ampütasyon ve ölümle sonuçlanır. Bu çalışmada, bacakta ağrı, şişlik ve morarma şikayetleri ile acil servise başvuran ve derin ven trombozunun hayatı tehdit eden bir komplikasyonu olan phlegmasia cerulea dolens tanısı alan olgu sunulmuştur. Hızlı tanı konularak hemen tedaviye başlanması bu hastalarda kangren, ampütasyon, pulmoner emboli ve ölümün önlenmesinde oldukça önemlidir.

Anahtar Kelimeler: Phlegmesia cerulea dolens, tanı, tedavi Geliş Tarihi: 05.01.2012 Kabul Tarihi: 03.03.2012

\section{Giriş}

Phlegmasia cerulea dolens (mavi flebit) derin ven trombozunun ciddi ve nadir görülen bir formudur (1). İskemik venöz tromboz da denilen bu tablo yoğun venöz tıkanıklık ile karakterizedir. Uygun profilaksi ve tedavi yaklaşımlarına rağmen, trombotik sürecin ilerlemesi ile ekstremitede kangren, ampütasyon (sağ kalanların \%12-25) ve ölüm (\%25-32) ile sonuçlanabilir (2). Bu hastaların tedavisinde günümüzde çok farklı tedavi yöntemlerinin genellikle birkaç kombinasyonu kullanılmaktadır. Bu tedaviler, antikoagülanlar, intravenöz trombolitikler, trombolitikler ile perkütan girişimler, venöz trombektomi, ekstremite elevasyonu ve bu tedavilerin kombinasyonu olarak uygulanır. Sonuçta venöz kangren gelişirse ampütasyon da diğer bir tedavi seçeneğidir (3). Günümüzde standart medikal ve cerrahi tedaviler venöz oklüzif hastalıkta çoğunlukla yeterli sonuç vermediği için alternatif tedaviler geliştirilmeye çalışılmaktadır.

Bu çalışmada, bacakta ağrı, şişlik ve morarma şikayetleri ile acil servise başvuran ve derin ven trombozunun hayatı tehdit eden bir komplikasyonu olan phlegmasia cerulea dolens tanısı alan olgu sunulmuştur.

\section{Olgu Sunumu}

Elli bir yaşında bayan hasta yedi gün önce başlayan öksürük, balgam, nefes darlığı ve son üç gündür de sol ayaktan başlayan ve diz altına kadar uzanan morarma, ağrı ve şişlik şikayetleri ile acil servisimize başvurdu. Hikayede hastanın yatalak olduğu ve bir bakım evinde kaldığı öğrenildi.

Hastanın başvurusunda kan basıncı 125/80 mmHg, nabzı 120 atım/dakika, ateşi $36.9^{\circ} \mathrm{C}$, solunum sayısı 34 sayı/dakika ve oda havasındaki oksijen saturasyonu \%84 olarak kaydedildi. Hastanın sistemik muayenesinde, akciğerlerde dinlemekle bilateral 
yaygın inspiratuar ral mevcuttu. Her iki alt ekstremite plejikti. Sol alt ekstremitede bacak dize kadar soğuk, soluk, ödemli ve siyanotikti. Ayrıca sol ayak dorsal yüzden itibaren bacak 1/3 distal kısma kadar olan bölgede çapı 1-3 cm arasında değişen çok sayıda büllöz lezyon mevcuttu (Resim 1). Hastanın sol femoral, popliteal, dorsalis pedis ve tibialis anteriorda nabızlar palpe edilemedi.

Hastanın başvuru sırasında beyaz küre sayısı 10600/mm³ (normal değeri 4.3-10.3/ $\mathrm{mm}^{3}$ ), trombosit sayısı 66000/ $\mathrm{mm}^{3}$ (normal değeri 156$373 / \mathrm{mm}^{3}$ ) C-reaktif protein $87.9 \mathrm{mg} / \mathrm{dL}$ (normal değerleri 0-0.8 mg/ dL), D-dimer 36 mqFEM (normal değerleri 0-0.7 mqFEM) olarak saptandı. Arteriyel kan gazlarında ise $\mathrm{pH}$ 7.437, parsiyel $\mathrm{CO}_{2} 31.1 \mathrm{mmHg}$, parsiyel $\mathrm{O}_{2} 46.8 \mathrm{mmHg}, \mathrm{HCO}_{3} 20.5 \mathrm{mmol} / \mathrm{L}$ ve oksijen saturasyonu \%84.8 olarak saptandı. Hastanın bunun dışındaki tam kan, elektrolit, glikoz, böbrek ve karaciğer fonksiyon testleri normal sınırlardaydı.

Hastanın elektrokardiogramfideki ritmi sinüs taşikardisiydi. Posterior anterior akciğer grafisinde sol hemitoraksın tamamında ve sağ hemitoraksın üst ve orta zonunda yaygın, dağınık yerleşimli yamalı infiltrasyon alanları mevcuttu (Resim 2). Çekilen toraks bilgisayarlı angiografisinde her iki pulmoner arter ve segmenter dallar açık izlendi. Sol alt ekstremite arteriel ve venöz doppler ultrasonografide arteriyel trombüs yoktu. Fakat venöz sistemde sol ana femoral, yüzeyel femoral, derin femoral ve popliteal vende lümen içerisinde hipoekoik, akım geçişine izin vermeyen trombüs ile uyumlu görünüm mevcuttu.

Hasta pnömoni ve phlegmesia cerulea dolens tanıları ile göğüs hastalıkları kliniği yoğun bakımına yatırıld. Hastaya kalp damar cerrahi kliniğinin önerisi ile aynı gün femoral ven kateterize edilerek selektif doku plazminojen aktivatörü (tPA) verildi ve sonrasında 18 Ü/kg/saatten heparin infüzyonu ve pnömoni tedavisi için intravenöz antibiyotik başlandı. Kontrol venografide tıkanıklığın devam etmesi üzerine fasiyotomi yapıldı. Tüm bu girişimlere rağmen üçüncü günde demarkasyon hattı gelişen hastaya diz seviyesinde ampütasyon yapıldı. Post operatif herhangi bir komplikasyon gelişmeyen, kliniği ve

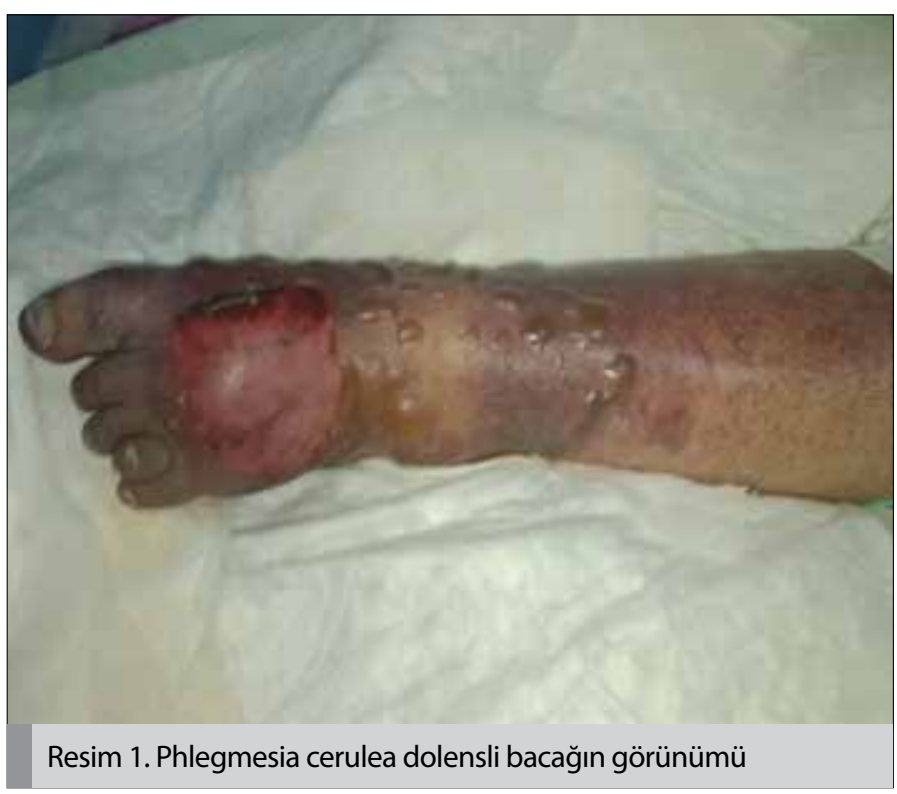

radyolojisi düzelen hasta onaltıncı gün sonunda enoxaparin sodyum tedavisi verilerek şifa ile taburcu edildi (Resim 3).

\section{Tartışma}

Phlegmasia cerulea dolens alt ekstremitenin total ya da totale yakın venöz tıkanıklığının nadir bir formudur $(2,4)$. Phlegmasia cerulea dolens ve phlegmasia alba dolens olmak üzere iki tipi vardır (2). Phlegmasia alba dolens etkilenen ekstremitenin derin ve yüzeyel venöz sisteminin masif trombozisi ile karakterize bir durumdur ancak venöz kolleterallerde tıkanıklık yoktur. Bu nedenle ölüm ve ampütasyon gibi sonuçları nadirdir. Phlegmasia cerulea dolensde ise kolleteral venlerin tromboziside olaya iştirak ederek venöz kangren, arteryel tıkanıklık, hipovolemik şok gibi komplikasyonlara neden olur $(5,6)$.

Phlegmesia caerula dolense bağlı en sık görülen komplikasyon \%30 oranında pulmoner emboli ve yaşayanların \%12-25'inde gelişen uzuv kaybıdır (2). Literatürde her yaş grubunda (6 aylıktan 87 yaş arasında), en sık kadınlarda (K/E:4/3) ve sıklıkla sol bacakta geliştiği
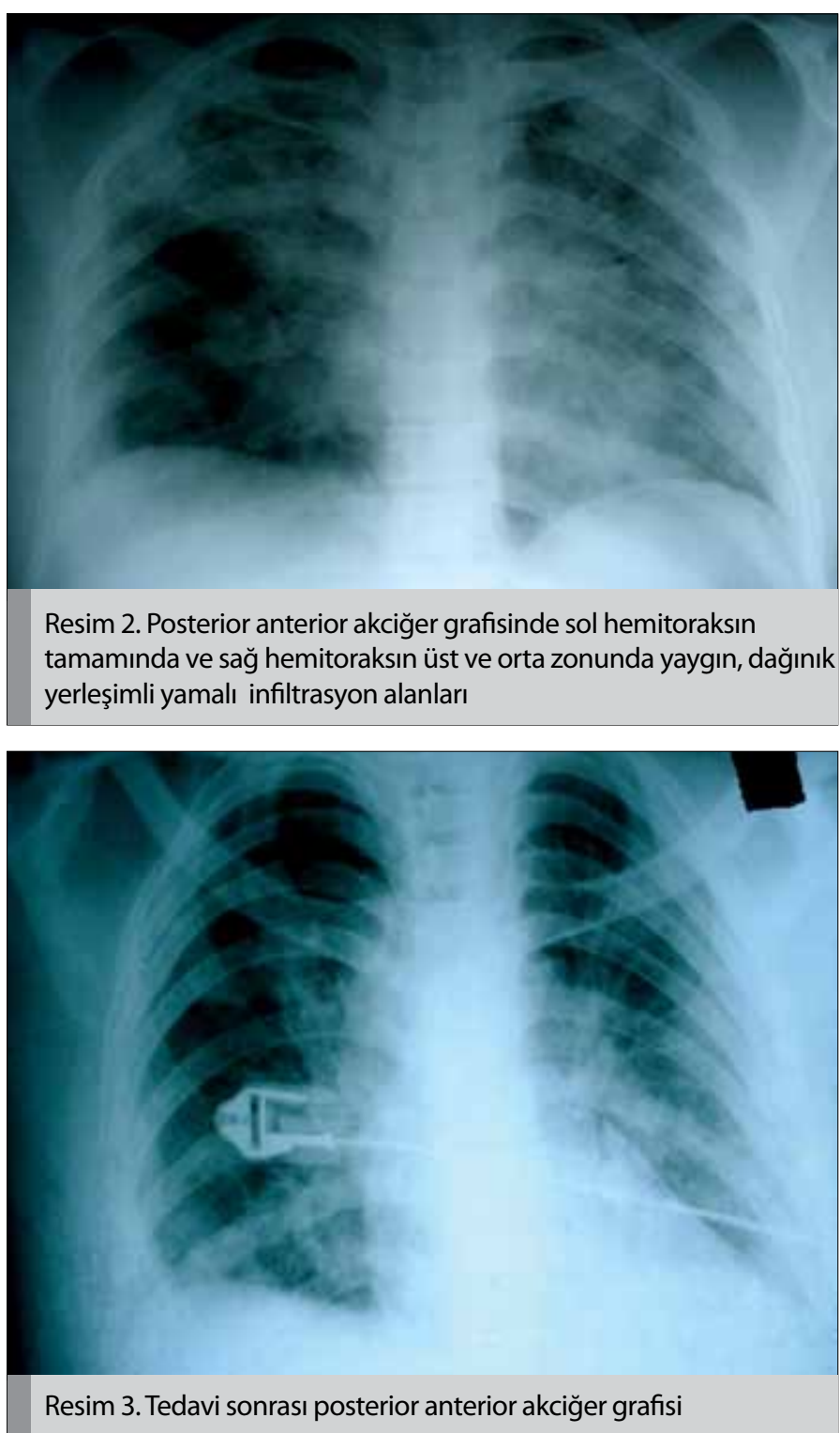
rapor edilmiştir (2). Burada tartışılan olgu bayan hasta ve sol bacakta gelişmişti. Hastada pulmoner emboli tespit edilmedi. Ancak hastada pnömoni kliniği olaya eşlik ediyordu.

Phlegmasia cerulea dolensli hastaların en yaygın tetikleyici faktör hiperkoagülopatilerdir. Özellikle malignensiler (yaklaşık \%20-40),cerrahi, lohusalık, protein C ve S eksikliği, antitrombin 3 eksikliği, travma, ülseratif kolit, gastroenterit, kalp yetmezliği, ciddi mitral stenoz, ilaç suistimali ve vena kavaya filtre yerleştirilmesidir (6). Bizim olgumuzda, immobilizasyon tetikleyici faktör olarak düşünülmüştür.

Ağrı, siyanoz, motor ve his kayıpları ön plandadır. Ağrı devamlı kramp ve gittikçe artan gerilme hissi şeklinde olup çok şiddetlidir. Birkaç gün içinde ekstremite içinde seröz mayi bulunan bleb veya büller oluşur. Phlegmasia cerulea dolens vakalarının \%40-60'ında kapiller tutulum olabilir ki bunlarda subkutan doku, kas ve deriyi içeren geri dönüşümsüz venöz kangren ile sonuçlanabilir (7). Ayrıca, bu vakalarda yoğun venöz tıkanıklık venöz sistemde hidrostatik basınç artışına sekonder olarak gelişen intersitisyel ödem artışı neden olur. Altı saat içinde tıkanıklığı takiben intravasküler basınçtaki artış ekstremitede kompartman sendromuna yol açar. Arteriyel dolaşımda yetmezlik, arteriyel doku iskemisi ve uzuv kaybı ya da ölüme neden olan kangren ile sonuçlanır (1). Hastalarda nabız sıklıkla alınmaz ve sadece hastaların \%17'sinde palpe edilebilir (2). Burada tartışılan olguda, sol bacak distalinde ve sol ayak dorsalin yüzde farklı büyüklüklerde çok sayıda büllöz lezyon ve diz altından itibaren siyanoz mevcuttu. Hastada, başvuru sırasında sol bacakta venöz kangren ve kompartman sendromu gelişmişti. Sol bacakta periferik nabızlar alınamıyordu.

Phlegmasia caerulea dolens tanısı klinik olarak konur. Ancak venöz sistem doppler ultrasonografisi ile tanı doğrulanmalıdır. Doppler ultrasonografide, etkilenen ekstremitenin derin ve yüzeyel venöz sistemde yoğun trombüs izlenir. Ven lümeninin komprese edilememesi ven içindeki trombüs için patognomoniktir (8).

Tedavi ile ilgili belirlenmiş algoritmler yoktur ve tedavi eden klinisyenin uzmanlığına göre yapılmaktadır. Bu tedaviler; hastanın klinik durumuna göre bacak elevasyonu, medikal antikoagulan tedavi, intravenöz trombolitikler, trombolitikler ile perkütan girişimler ve tromboembektomi ya da bu tedavilerin kombinasyonunu içermektedir (7, 9-12). Eğer tüm bu tedavilere rağmen venöz kangren gelişirse ampütasyon diğer bir tedavi seçeneğidir. Phlegmasia caerulea dolens tedavisinde kompartman sendromu gelişiminin, bacak iskemi riskindeki artışın ve tromboz yayılımının önlenmesi hedeflenir (13). Bizim vaka da hastanın acile başvuru sırasında kompartman sendromu gelişmiş olması nedeniyle önce girişimsel radyoloji tarafından femoral ven kateterize edilerek selektif trombolitik tedavi uygulan- dı. Göğüs hastalıkları kliniği tarafından takip edilen hastaya bacak elevasyonu yapıldı, 18Ü/kg dozunda heparin infüzyonu ve $300 \mathrm{mg} /$ gün salisilik asit verildi. Ancak tüm bu tedavilere rağmen takibinin üçüncü gününde hastanın bacağında demarkasyon hattı oluştu ve hastaya diz seviyesinde ampütasyon uygulandı.

\section{Sonuç}

Phlegmesia cerulea dolens nadir görülen ancak erken tanı konulamadığında yüksek morbidite ve mortalitesi nedeniyle kötü seyirli bir hastalıktır. Hızlı tanı konularak hemen tedaviye başlanması bu hastalarda kangren, ampütasyon, pulmoner emboli ve ölümün önlenmesinde oldukça önemlidir.

\section{Çıkar çatışması}

Yazarlar herhangi bir çıkar çatışması bildirmemişlerdir.

\section{Kaynaklar}

1. Mahomed A,Williams D. Phlegmasia caerulea dolens and venous gangrene. Br J Surg 1996; 83: 1160-1. [CrossRef]

2. Perkins JM, Magee TR, Galland RB. Phlegmasia caerulea dolens and venous gangrene. Br J Surg 1996; 83: 19-23. [CrossRef]

3. Gutt CN, Oniu T, Wolkener F, Mehrabi A, Mistry S, Büchler MW. Prophylaxis and treatment of deep vein thrombosis in general surgery. Am J Surg 2005; 189: 14-22. [CrossRef]

4. Bang C. Lower and upper extremity deep venous thrombosis evaluation. In: Dogra V, Rubens DJ,editors. Ultrasound secrets.1st edition. Philadelphia:Hanley \& Belfus; 2004.p.337.

5. Hood DB, Weaver FA, Modrall JG, Yellin AE. Advances in the treatment of phlegmasia cerulean dolens. Am J Surg 1993; 166: 206-10. [CrossRef]

6. Lorimer JW, Semelhago LC, Barber GG. Venous gangrene of the extremities. Can J Surg 1994; 37: 379-84.

7. Comerota AJ, Aldridge SC, Cohen G. A strategy of aggressive regional therapy for acute iliofemoral venous thrombosis with contemporary venous thrombectomy or catheter-directed thrombolysis. J Vasc Surg 1994; 20: 244-54. [CrossRef]

8. Fraser JD, Anderson DR. Deep venous thrombosis: recent advances and optimal investigation with US. Radiology 1999; 211: 9-24.

9. Tardy B, Moulin N, Mismetti P, Decousus H, Laporte S. Intravenous thrombolytic therapy in patients with phlegmasia caerulea dolens. Haematologica 2006; 91: 281-2

10. Lin SC, Mousa A, Bernheim J, Dayal R, Henderson P, Hollenbeck S, et al. Endoluminal recanalization in a patient with phlegmasia cerulea dolens using a multimodal approach. Vasc Endovasc Surg 2005; 39: 273-9. [CrossRef]

11. Centeno RJ, Nguyen AH, Ketterer C, Stiller G, Chait A, Fallahnejad M. An alternative approach: antegrade catheter-directed thrombolysis in a case of phlegmasia cerulea dolens. Am Surg 1999; 65: 229-31.

12. Chinsakchai K, Ten Duis K, Moll FL, de Borst GJ. Trends in management of phlegmasia cerulea dolens. Vasc Endovascular Surg 2011; 45: 5-14. [CrossRef]

13. Bird RL, Hamilton G. Treatment options for phlegmasia cerulea dolens. $J$ Vasc Surg 1995; 21: 998-9. [CrossRef] 